\title{
CHARLIE HEBDO, SECULARIZAÇÃO E ESCATOLOGIA
}

\author{
FABIO MOURILHE \\ UNIVERSidAde FEDERAL do RIO DE JANEIRO (UFRJ)
}

\begin{abstract}
RESUMO: Este trabalho tem por objetivo tratar dos aspectos relacionados à prática e ao espírito do Charlie Hebdo por ocasião do assassinato de membros de sua equipe. Para atingir tal intento, consideramos de antemão a modernidade como aquela que se apropria do padrão escatológico cristão de forma secularizada, tal qual é apontado por Löwith, o que indica uma especificidade para as ideias de "fim da história" e "fim da arte" em Hegel. Os objetivos específicos incluem apresentar o semanário, delimitar as características e consequências do atentado, determinar os aspectos mais significativos indicados pela comissão sobre laicidade, analisar o extremismo islâmico e suas polarizações, e verificar o método específico do Charlie Hebdo de combate ao extremismo. A prática da secularização na França atual serviria para justificar e defender os posicionamentos assumidos no Charlie Hebdo. A escatologia moderna, presente nas ideias de fim da arte e fim da história, permite que nos aprofundemos na questão. Não se pode falar em um fim sem que se considere um começo, pois aqui há sobrevivência e morte. Com artistas que expõem sua opinião e, mesmo sabendo que correm risco, pagam com a própria vida, temos uma proximidade com a concepção do humor, como a destruição da arte por ela mesma.
\end{abstract}

PALAVRAS-ChAVE: Charlie Hebdo, Fim da Arte, Escatologia, Secularização.

ABSTRACT: This study aims to address the aspects related to the practice and spirit of Charlie Hebdo on the occasion of the murder of some of their members. To achieve this purpose, we consider beforehand modernity as an appropriation of the Christian eschatological pattern in a secularized form, as appointed by Löwith, indicating specificity to the ideas of "end of history" and "end of art" in Hegel. The specific objectives include presenting the journal, defining the characteristics and consequences of the attack, determining the most significant aspects indicated by the committee on secularism, analyzing Islamic extremism and its biases, and checking the specific method of Charlie Hebdo to combat extremism. The practice of secularization in France today would justify and defend the positions taken in Charlie Hebdo. Modern eschatology, present in the ideas of "end of art" and "end of history", allows us to delve into the issue. We can not speak of an end without considering a start, for there are survival and death. With artists exposing their opinion and, even though they are at risk, paying with their lives, we have a proximity to the concept of humor, as the destruction of art by itself.

KEYWORDS: Charlie Hebdo, End of Art, Eschatology, Secularization. 


\section{Introdução}

Charlie Hebdo é um jornal de humor que se insere no panorama cultural, social e político da França, onde a secularização está presente. O objetivo deste trabalho é tratar do espírito do jornal e de sua relação com a escatologia moderna na forma de fim da arte ou fim da história, conforme exposto por Hegel em seus estudos. Os objetivos específicos são: apresentar o semanário, baseando-se na pesquisa de Jane Weston e depoimentos de François Cavanna; delimitar as características e consequências do atentado, a partir de reportagens, incluindo parecer de Slavoj Žižek; determinar os aspectos mais significativos indicados pela comissão sobre laicidade, expostos no livro de Emerson Gumbelli; analisar o extremismo islâmico e suas polarizações a partir do pensamento de Žižek, Alain Badiou, Giorgio Agamben e Vladimir Safatle; e verificar o método empregado pelos membros do Charlie Hebdo para combater o extremismo, a partir do posicionamento de Olivier Tonneau e Josselin Moneyron.

A prática da secularização na França atual serviria para justificar e defender os posicionamentos assumidos no Charlie Hebdo. A escatologia moderna, presente nas ideias de fim da arte e fim da história, permite que nos aprofundemos na questão. Não se pode falar em um fim sem que se considere um começo, pois aqui há sobrevivência e morte. Com artistas que expõem sua opinião e, mesmo sabendo que correm risco, pagam com a própria vida, temos uma proximidade com a concepção do humor, como a destruição da arte por ela mesma.

\section{Modernidade como época secularizada}

Percebe-se, na França e outros países do mundo, a modernidade como época secularizada, onde os elementos sagrados e aspectos transcendentes são abandonados, tendo em vista a ênfase na cultura, mas também na arte e na ciência - secularização como norma.

Diferente do significado utilizado no Direito canônico para "secularização" - de uma "dispensa dos votos religiosos a um clérigo regular e sua incardinação numa diocese no clero secular" ${ }^{1}$, utilizaremos o termo conforme a atribuição recebida com a revolução francesa: "expropriação das propriedades eclesiásticas pelo governo revolucionário. Aqui o termo possui uma conotação negativa de ilegitimidade do ato, já que as terras e propriedades expropriadas pertenciam legitimamente à Igreja" ${ }^{\prime 2}$. Trata-se de uma secularização como processo pautado pela exclusão dos vínculos religiosos, por meio da supressão da ideia de transcendência e de vida pós-morte.

\footnotetext{
${ }^{1}$ SOUZA, José Carlos Aguiar de. As filosofias da história e a tese da secularização: a teologia cristã e as raízes da secularização na modernidade. In: PLURA, Revista de estudos da religião, vol. 2, n. 2, 2011, p. 45.

${ }^{2}$ Ibid.
} 
Nesse processo de secularização, também tivemos, de forma semelhante à prática de expropriação das propriedades eclesiásticas na época da revolução francesa, posteriormente, a invasão e a conquista de terras, algumas com predominância muçulmana, que continuou a ser colocada em ação pelos colonizadores europeus, incluindo a França. Além disso, membros desses povos conquistados também passaram a viver na França. Seus costumes religiosos entram em conflito com outras religiões e o ateísmo na esfera pública francesa.

Outra opção é utilizar a secularização como categoria interpretativa, o que é realizado por Karl Löwith em Meaning in history, de 1949. Segundo Souza $^{3}$, Löwith indica a modernidade como aquela que se apropria do padrão escatológico cristão de forma secularizada, o que poderia ser percebido nas filosofias da história apresentadas na dialética hegeliana e na luta de classe marxista. Essas filosofias seguem o "padrão teleológico cristão", porém deixam "Deus de fora".

O "fim da história" e o "fim da arte" em Hegel servem para pensar de forma especial essa apropriação secularizada do padrão escatológico cristão, considerando o acúmulo que se dá tanto em arte como na história antes de seu fim, e as relações entre religião e arte, e humor/comédia e arte.

O fim da história em Hegel aponta para o entendimento da história em sua totalidade ${ }^{4}$, o que permite atingir o saber absoluto ${ }^{5}$ com uma tomada de consciência de si pelo espírito absoluto. A história passa por movimentos dialéticos, com novas realidades entrando em cena, se confrontando, se opondo e se negando.

Costa $^{6}$ mostra as interpretações de Perry Anderson e Paulo Eduardo Arantes sobre a Fenomenologia do espírito, em que a história é tida como "palco de uma evolução consciente do espírito, por meio de uma sucessão de formas temporais específicas, até atingir a meta do conhecimento absoluto" por meio de um "desdobramento reflexivo", o que também ocorre no fim da arte, com sua integração ao pensamento reflexivo, uma emergência da reflexão sobre arte corresponde ao surgimento da filosofia da arte. A história brota da sociedade junto a uma "tomada de consciência", uma mudança que leva o "indeterminado ao determinado", no que tange à objetividade e subjetividade.

A poesia dramática, por exemplo, para $\mathrm{Hegel}^{7}$, seria o supremo estágio da poesia e da arte em geral, que traz em si tanto a objetividade da epopeia (poesia épica) como a subjetividade da lírica (poesia lírica). Trata-se da natureza dupla do drama, com momentos distintos de afirmação histórica que o constituem.

\footnotetext{
${ }^{3}$ Ibid., p.46.

${ }^{4}$ Com um esforço histórico total, é possível alcançar a realidade total.

${ }^{5}$ Quando temos uma coincidência entre sujeito cognoscente e objeto conhecido.

${ }^{6}$ COSTA, Renata de Pina. O fim da arte na filosofia hegeliana. Dissertação de mestrado em Filosofia. Curitiba: Universidade Federal do Paraná, 2009, p. 18.

${ }^{7}$ HEGEL, Georg Wilhelm Friedrich. Cursos de Estética, vol. IV. São Paulo: Edusp, 2004, p. 200.
} 
Mantém em si os dois lados. "A determinidade do ânimo se dirige aos impulsos, à efetivação do interior por meio da vontade, à ação" ${ }^{\prime 8}$ e às relações humanas, que se tornam exteriores e se objetivam. Pela ação são executados os propósitos e fins interiores. O sujeito consigo mesmo e também o seu si mesmo que passa para a existência exterior. "O indivíduo dramático colhe ele mesmo os frutos de seus próprios atos" ${ }^{\prime 9}$. Permite a expressão dos homens na luta por seus interesses e na cisão de suas paixões ${ }^{10}$ na exposição do divino em sua relação mundana e leva à emergência do ético. Nesse confronto, os heróis trágicos seriam, segundo Hegel ${ }^{11}$ tanto culpados como inocentes, agindo em conformidade com seu pathos - aqui, segundo Gonçalves ${ }^{12}$, poder divino incorporado ou potência ética - e se afastando de um ato consciente de escolha. "Os deuses se transformam em pathos humano e o pathos em atividade concreta é o caráter humano"13.

Existe a possibilidade de aproximar a prática do Charlie Hebdo a essa natureza dupla do drama, no que tange ao caráter impulsivo dos cartunistas do semanário, que almejam uma expressão ética exterior. O fim do jornal, apesar de ser sustentado no momento atual, aparece como fato muito mais concreto no final de sua primeira fase, com o desequilíbrio do subjetivo e do objetivo, e a ênfase da comédia, tida por Hegel como a degeneração da arte. Vejamos agora o que está incluído no espírito do Charlie Hebdo e como o processo de secularização se dá na França atual.

\section{Contextualização histórica}

Charlie Hebdo sempre apresentou um humor ilustrado corajoso em suas duas fases, de 1969 a 1982, e a outra, a partir de 1992. Em ambas, temos uma prática gráfica com características que persistiram graças à permanência de alguns dos cartunistas originais. Caracteriza-se pelo humor conhecido como estúpido e desagradável (bête et méchant, marca satírica provocativa), alcunha concebida no começo da década de 1960 na revista de humor Hara-Kiri, como seu subtítulo. $O$ humor bête et méchant favorece, segundo Weston ${ }^{14}$, a abertura para cartuns que empregam o sexo explícito e um humor negro ${ }^{15}$. François Cavanna ${ }^{16}$ - fundador do Hara-Kirie do Charlie Hebdo junto a Georges

\footnotetext{
${ }^{8}$ Ibid., p. 203.

${ }^{9}$ Ibid.

${ }^{10}$ Ibid., p. 212.

${ }^{11}$ Ibid., p. 254.

12 GONÇALVES, Márcia Cristina Ferreira. $O$ belo e o destino: uma introdução à filosofia de Hegel. São Paulo: Edições Loyola, 2001, p. 301.

${ }^{13}$ HEGEL, Georg Wilhelm Friedrich. Cursos de estética, vol. I. São Paulo: EdUSP, 2001, p. 241.

14 WESTON, Jane. Bête et méchant. Politics, editorial cartoons and bande dessinée in the French satirical newspaper Charlie Hebdo. In: European Comic Art 2 (2009), p. 109.

${ }^{15}$ Segundo Weston (ibid., p. 114), o espírito bête et méchant ressoa nas ideias presentes no existencialismo, com sua rejeição das noções de sagrado e sua dúvida radical que questiona os fundamentos de uma sensibilidade moral conservadora.

${ }^{16}$ Apud WESTON, Jane. Op. cit., p. 110.
} 
Bernier - justifica a postura do grupo como uma força dessacralizadora, que permite rir de qualquer tema, mesmo do tabu:

Nada é sagrado. Princípio número um. Nem mesmo a sua própria mãe, nem os judeus, mártires, nem mesmo as pessoas que passam fome... Ria de tudo, ferozmente, amargamente, para exorcizar os velhos monstros. Teríamos respeito demais com eles se nos aproximássemos de cara limpa. É exatamente das piores coisas que devemos rir mais alto, é onde dói mais que você deve coçar até sangrar.

Esse estilo radical esteve presente, segundo Weston ${ }^{17}$, no Hara-Kiri e na primeira fase de Charlie Hebdo. Em contraste, na segunda fase de Charlie temos o espírito original apenas em parte, pois adquire um tom menos juvenil e satírico, com menos piadas gratuitas e maior seriedade, principalmente quando Philippe Val foi editor.

Em termos criativos, temos tanto na Hara-Kiri como no Charlie Hebdo desenhos em painéis únicos, tiras, quadrinhos, fotomontagens, prosas curtas humorísticas e paródias. Cavanna ${ }^{18}$ salienta também seu apreço e a presença do desenho mudo - como em Bosc -, sem palavras e sem diálogo, vivendo "por si só", onde o "leitor é que deve estar rindo e não o desenho". A sobreposição de cartuns presente nessas publicações é tratada por Reiser ${ }^{19}$ como "cartuns sequenciais", que quebram com o cânone dos limites entre cartuns de humor e histórias em quadrinhos.

\section{Início do conflito e lei da laicidade}

Os atritos e conflitos mais incisivos entre o Charlie Hebdo e os islâmicos começaram em 2002, quando foi publicado um artigo sobre o livro de Oriana Fallaci, La rage et l'orgueil. A matéria falava da coragem da escritora em protestar contra o "islamismo assassino". O jornal passou a ser perseguido pela União das Organizações islâmicas e receber ameaças constantes de grupos extremistas islâmicos.

De forma ampla, a tensão em torno da questão islâmica pode ser percebida no relatório da Comissão sobre a laicidade criada pela presidência da república na França, conforme mostra Giumbelli ${ }^{20}$. A comissão, a partir do segundo semestre de 2003, realizou audiências abertas e privadas com representantes de diversas frentes. Foram consideradas aqui a presença da religião e seu tratamento pela sociedade francesa.

\footnotetext{
${ }^{17}$ Ibid.

${ }^{18}$ CAVANNA, François. Bête et méchant. Paris: Éditions Pierre Belfond, 1981.

${ }^{19}$ Apud WESTON, Jane. Op.cit., p. 124.

${ }^{20}$ GIUMBELLI, Emerson. Religião, estado, modernidade: notas a propósito de fatos provisórios. In: Estudos avançados. Estud. Av., Vol. 18, n. 52, São Paulo, Set/Dez. 2004.
} 
Constatou-se um pluralismo do campo religioso e espiritual. Além do catolicismo e outras religiões, nota-se a força da presença do islamismo, e também os "ateus, agnósticos e livres pensadores". Foi reconhecida nesse contexto "uma desigualdade no modo como essas diferentes expressões religiosas e espirituais estão presentes na sociedade francesa", com uma ênfase que

recai sobre o islamismo, geralmente desfavorecido pela insuficiência de lugares de culto, pelo não reconhecimento oficial de seus feriados, pela carência no atendimento de suas especificidades rituais em escolas, hospitais, prisões, quartéis, em refeitórios coletivos e cemitérios públicos - e ainda pela desvantagem social e cultural das populações de origem muçulmana que formam a maior parte dos seus adeptos ${ }^{21}$.

O problema do "comunitarismo", visto como um perigo, também é ressaltado no relatório. Indica uma dinâmica social em que é exacerbada a identidade cultural, com especificidade para as populações desfavorecidas, "entre as quais se encontrariam exemplos de uma reação que implica colocar as 'tradições' acima dos indivíduos", em um mesmo território onde os indivíduos têm convicções diversas. Envolve a incongruência de dispor uma comunidade fechada em uma sociedade incompatível.

Segundo Giumbelli ${ }^{22}$, a laicidade aqui em questão seria um valor comum necessário. No documento, ela envolve a garantia de um limite para a religião. Em termos de separação entre estado e religião, mostra a necessidade de algum envolvimento mínimo.

Se a separação assegura que as opções espirituais ou religiosas não envolvam o Estado e que este não se envolva com aquelas, ela demanda também que o Estado cuide das condições de possibilidade da expressão religiosa, assim como postula a renúncia das religiões à sua dimensão política. A laicidade pede a cada uma das religiões um esforço de adaptação e de conciliação de seus dogmas com as leis que regem a sociedade.

Em termos de igualdade, temos a exigência de "um tratamento isonômico por parte do Estado", mas, também, que as religiões "não façam demandas particularistas".

Em termos de liberdade de consciência, temos a exigência das condições necessárias para o funcionamento normal da instituição religiosa e direito à livre expressão religiosa no espaço e no debate públicos, mas, também, a necessidade de proteção do indivíduo pelo Estado contra toda imposição religiosa.

Essa comissão, composta por funcionários, militantes e intelectuais de diversas especialidades, ouviu representantes políticos, religiosos, sindicais, administrativos e associativos, o que permitiu a elaboração de um panorama

${ }^{21}$ Ibid.
22 Ibid. 
esclarecedor sobre a situação religiosa e a laicidade na atualidade. Aponta para recomendações em eixos distintos. Por um lado, pretende-se reforçar "a neutralidade do Estado, especialmente nas regras aplicadas aos servidores e serviços públicos", com servidores que devem suspender suas opiniões pessoais, políticas e filosóficas, inclusive as religiosas, e também "limitar 0 espaço de expressão da religião e deixar o funcionamento de instituições públicas imunes às suas influências e demandas". Temos aqui uma ênfase na preocupação com a ordem pública. Por outro lado, exige-se a colocação do Estado como um fator direto de intervenção no campo religioso, com medidas como

a criação de uma "escola nacional de estudos islâmicos", a habilitação de capelães muçulmanos em instituições coletivas em regime de internato, a adequação de estabelecimentos públicos para atender a exigências religiosas em matéria de alimentação e rituais funerários, a inclusão de mais dois feriados no calendário nacional (correspondentes a datas sagradas no judaísmo e no islamismo $)^{23}$.

No papel de conselheiro que oscila entre dois eixos opostos, essa Comissão assumiu uma função complexa. Em 2004, por exemplo, depois de muitos conflitos envolvendo questões religiosas no âmbito escolar foram proibidos por lei nas escolas públicas "os trajes e signos manifestando um pertencimento religioso ou político". O véu para eles seria não apenas um símbolo religioso, "mas o indício da dominação da família e dos grupos comunitários sobre os indivíduos, dos homens sobre as mulheres". E, afirma o relatório, "o espaço escolar deve permanecer para elas [as alunas] um lugar de liberdade e de emancipação".

A lei que modificou o Código da Educação foi promulgada em março de 2004 com o seguinte texto: "(nas escolas públicas), o porte de signos e trajes pelos quais os alunos manifestam ostensivamente um pertencimento religioso é interdito". Foi essa lei - que passaria a valer no reinício das aulas em setembro, gerando enorme expectativa - que teve sua revogação exigida por sequestradores de jornalistas franceses no Iraque na época ${ }^{24}$.

A proposta dessa Comissão e as discussões e os conflitos suscitados aqui servem para mostrar o panorama específico em que o Charlie Hebdo se posicionou ao longo de toda a década, envolvendo uma briga contínua entre charges e ameaças de morte, que culminou no atentado, como veremos a seguir.

${ }^{23}$ Ibid.

${ }^{24}$ Ibid. 


\section{Atentado e morte}

Em novembro de 2011, a sede do jornal já tinha sido atacada e destruída com um coquetel molotov e o site do jornal, também vítima de um ataque, teve sua home page substituída por uma foto da Meca e textos do Alcorão. Tudo devido à nova edição publicada pelo Charlie nessa data com uma capa que trazia uma caricatura de Maomé e o convite para que ele participasse como editor da revista, com a chamada "cem chibatadas se você não morrer de rir" e a mudança do nome para Charia Hebdo, numa alusão à palavra sharia, sistema legal islâmico. Charb, editor desde 2009, vivia sob escolta policial. Em 2013, ele foi adicionado à lista dos mais procurados pela Al-Qaeda.

Uma charge premonitória foi publicada em data próxima ao atentado no começo de 2015. A partir do questionamento "nenhum ataque na França ainda?", temos um extremista respondendo: "Calma, ainda podemos mandar nossas felicitações até o fim de janeiro".

No dia 7 de janeiro de 2015, com uniforme militar de cor preta, encapuzados, armados com fuzis Kalashnikov (AK-47) e um lançador de granadas, os irmãos Kouachi (franceses de origem argelina) invadiram a redação do Charlie e executaram um total de 12 pessoas, entre as quais Cabu, Honoré, Tignous, Wolinski e Charb, e deixaram 11 feridos. Foi um dos piores atentados na França nos últimos 50 anos, desde a guerra da Argélia. Segundo Carta $^{25}$, a França viveu o seu 11 de setembro.

A noite, reuniram-se na Praça da República em Paris 35 mil pessoas para se manifestar contra o terrorismo. Idem em Lyon, Toulouse c outras cidades da França e do mundo. Em 11 de janeiro de 2015, cerca de três milhões de pessoas em toda a França fizeram uma grande manifestação para homenagear as 17 vítimas dos três dias de terror.

Le Monde e a rede de TV Canal+ apoiaram a publicação do Charlie Hebdo na quarta-feira seguinte ao atentado. A previsão seria de um milhão de exemplares ao invés dos habituais 60 mil, com oito páginas no lugar das costumeiras 16. Liberation ofereceu espaço à equipe de Charlie Hebdo ${ }^{26}$. Nessa edição, temos um desenho de Luz com Maomé chorando e segurando o cartaz Je suis Charlie, e a legenda "Está tudo perdoado". Em toda a Europa, a nova edição teve boa aceitação, mas sua venda está proibida em países como Egito e Argélia.

\footnotetext{
${ }^{25}$ CARTA, Gianni. Chore por mim, França. In: Revista Carta Capital, n. 833. Ano XXI. 21 de janeiro de 2015, p. 21.

${ }^{26}$ Da mesma forma como procedeu em novembro de 2012 após o incêndio provocado por um coquetel Molotov na velha sede.
} 


\section{Espetáculo de domingo}

Posteriormente ao atentado também tivemos o que Žižek ${ }^{27}$ chama de um "espetáculo de domingo". Diversas personalidades políticas do cenário mundial apareceram juntas em 11 de janeiro de 2015 para apoiar os mortos no atentado e condenar conjuntamente 0 terrorismo. Para Carta ${ }^{28}$, várias autoridades convidadas às pressas são líderes de países onde não existe liberdade. Segundo Žižek ${ }^{29}$, temos aqui uma caricatura em que personalidades se beijam intensamente enquanto enfiam facas pelas costas. "O espetáculo foi literalmente encenado: as fotos expostas na mídia davam a impressão de que a linha de líderes políticos estava na frente de uma grande multidão que marchava pela avenida - dando, assim, a impressão de uma suposta solidariedade e união com o povo" ${ }^{\prime 30}$.

Sem considerar a diferença entre as fases distintas da publicação aparentemente não as conhece ou conhece apenas as charges mais polêmicas e problemáticas, Žižek ${ }^{31}$ toma Charlie Hebdo como publicação estritamente "estúpida e maldosa" (bête et méchant) que viola os dez mandamentos, mas descola o slogan de forma apropriada para Je suis bête et méchant a ser incorporado aos políticos em desfile no domingo. As autoridades israelenses, por exemplo, conforme mostra Shihade ${ }^{32}$, estariam felizes com esse desfecho, pois poderiam "utilizar os atentados na sua manipulação cínica de tentar unir o mundo inteiro contra os palestinos... Nesse meio-tempo, os palestinos continuam subjugados à repressão e assassinatos, assim como milhões de árabes e muçulmanos".

Mino Carta ${ }^{33}$ trata o encontro de forma semelhante, como o triunfo da hipocrisia (je suis hypocrite), pois boa parte daqueles ali presentes

têm responsabilidades em relação ao terrorismo, quando não são seus instigadores, cúmplices ou até mesmo praticantes... Juntaram o Ocidente em uma praça parisiense para ostentar os seus poderes e cuidar dos seus interesses políticos, sem exclusão de golpes baixos, ações de guerra, assaltos aos cofres públicos e terrorismo de Estado, sem contar as violações dos direitos humanos.

27 ŽIŽEK, Slavoj. Pensar o atentado ao Charlie Hebdo. Blog da Boitempo. Disponível em: http://blogdaboitempo.com.br/2015/01/12/zizek-pensar-o-atentado-ao-charlie-hebdo/.

Acessado em 5/2/2015.

${ }^{28}$ CARTA, Gianni. Op. cit., p.22.

29 ŽIŽEK, Slavoj. Op.cit, loc. cit.

30 Idem. Eu sou estúpido e maldoso. Blog do Boitempo. 16/2/2015. Disponível em: http://blogdaboitempo.com.br/2015/02/16/eu-sou-estupido-e-maldoso-zizek-esclarece-suaposicao-sobre-o-je-suis-charlie/. Acessado em 19/2/2015.

${ }^{31}$ Ibid.

${ }^{32}$ Apud CARTA, Gianni. Op. cit., loc. cit.

${ }^{33}$ CARTA, Mino. Todos à la place. Por quê? In: Revista Carta Capital, n. 833. Ano XXI. 21 de janeiro de 2015, p. 15. 
O cenário se completa com o extremismo religioso propriamente dito, como efeito ou resultante da prática política.

\section{Extremismo islâmico em polarização em relação ao mundo}

A prática do terror tem por objetivo, segundo Laerte $^{34}$, criar um pandemônio que comprometa todo o sistema e movimente a opinião massiva. Exacerba-se, então, o sentimento xenófobo e gera políticas militares de intervenção no Oriente Médio. Está formado, então, um cenário de guerra que interessa ao Estado islâmico. Não existe interesse em construir uma coletividade e, sim, instaurar uma guerra contra o mundo. Tenta-se acirrar o choque entre as culturas, com uma ênfase na unilateralidade política, sua imposição sobre "o inimigo" e a tentativa de destruição desse inimigo. "Começam os ataques às mesquitas e restaurantes árabes, ou aos minimercados judaicos. Isso vai gerar um padrão estimulado por grupos de direita que querem construir uma política de exclusão dentro da Europa". Tanto os extremistas islâmicos como a direita xenófoba se alimentam desses conflitos.

Žižek ${ }^{35}$ realiza aproximação semelhante, porém entre fundamentalismo e liberalismo, tendo o primeiro como uma reação a um defeito do segundo, que considera a contraposição entre vida longa e satisfatória cheia de bem-estar material e cultura, e a reação fundamentalista à primeira com uma vida dedicada a alguma causa transcendente ${ }^{36}$, ou uma reação derivada da falência de valores fundamentais do liberalismo, como liberdade, igualdade e democracia ${ }^{37}$.

Badiou $^{38}$ também pensa de forma análoga, porém enfatiza o aspecto fascista do Estado Francês pós-pacto republicano ${ }^{39}$ e o associa ao Charlie Hebdo. Uma postura de secularização e dos ideais de liberdade, igualdade e fraternidade realmente ecoa em ambos, porém a culpa pela destruição e colonização de estados não pode ser atribuída ao Charlie Hebdo. A conclusão de que o estado, Ocidente e França, seriam tão terroristas quanto os

34 KACHANI, Morris. Laerte: no Brasil Charlie Hebdo não existiria. Disponível em: http://blogdomorris.blogfolha.uol.com.br/2015/01/09/laerte-no-brasil-charlie-hebdo-naoexistiria/. Acessado em 5/2/2015.

35 ŽIŽEK, Slavoj. Como lidar com os fundamentalistas hoje. Diário do centro do mundo. 10/1/2015. Disponível em: http://www.diariodocentrodomundo.com.br/como-lidar-comfundamentalistas-hoje-um-artigo-de-slavoj-zizek/. Acessado em 3/2/2015.

36 Žižek, contudo, neste artigo também apresenta uma condenação estranha aos "progressistas", indicando que esses deveriam assumir um ódio pelo Islã, como faz a extrema direita.

37 Idem, Pensar o atentado ao Charlie Hebdo. Blog da Boitempo. Disponível em: http://blogdaboitempo.com.br/2015/01/12/zizek-pensar-o-atentado-ao-charlie-hebdo/.

Acessado em 5/2/2015.

38 BADIOU, Alain. A farsa do Charlie Hebdo. Blog do Boitempo. Disponível em: http://blogdaboitempo.com.br/2015/02/04/o-vermelho-e-o-tricolor-alain-badiou-sobre-o-charliehebdo/. Acessado em 15/2/2015.

${ }^{39}$ Badiou (ibid.) mostra o crime fascista, de modo muito próximo ao exposto por Laerte, como aquele que cria "reações descontroladas" em uma vingativa contraidentidade. 
extremistas pode ser até discutida - apresentam papéis intercambiáveis ou identidades falsas entre criminoso e polícia -, na medida em que os primeiros enviam "selvagens expedições militares internacionais que destroem Estados inteiros" ${ }^{\prime 40}$. Charlie Hebdo, contudo, não pode ser responsabilizado por isso, pois os combate tanto quanto enfrenta o extremismo religioso. Safatle ${ }^{41}$ também, de forma pouco precisa, classifica erroneamente os cartunistas do Charlie Hebdo como racistas e preconceituosos. Ele não viu as charges em que os cartunistas delatam os abusos realizados contra as minorias na França. Cabu, por exemplo, tem um número de charges muito conhecidas e significativas, onde a polícia francesa - formada por skinheads - está escalada e em ação na repressão de minorias, o que exemplifica a denúncia vinculada pelo Charlie Hebdo contra as práticas de exclusão.

Com o atentado aos cartunistas do Charlie Hebdo, também temos a radicalização do conflito entre a "direita radical difusora da islamofobia e a esquerda, com a sua bandeira de integração centrada na formação de uma igualitária sociedade multiétnica"42. Essa direita populista é liderada na França por Marine Le Pen (Frente Nacional) e na Itália por Matteo Salvini da Liga Norte. Ambos são xenófobos, não distinguem entre islâmicos pacíficos e terroristas $^{43}$ e são favoráveis à revogação do Tratado de Schegen ${ }^{44}$. Marine, após o atentado, solicitou um referendo pedindo a aplicação da pena de morte aos responsáveis, prática abolida da França desde $1981^{45}$ e também criticou a "condescendência e omissão" do atual governo: "Este atentado deve liberar nossas palavras contra o fundamentalismo islâmico. A hipocrisia não é mais possível'$^{\prime 46}$.

\footnotetext{
40 Agambem (apud CARTA, op. cit., p.23) também pensa da mesma forma, mostrando que George Bush, por ter invadido o Iraque em 2003 e matado dezenas de milhares de pessoas, pode ser considerado responsável pelas mortes dos cartunistas do Charlie.

${ }^{41}$ SAFATLE, Vladimir. Palavras e metralhadoras. In: Revista Carta Capital, n. 833. Ano XXI. 21 de janeiro de 2015, p. 27.

42 MAIEROVITCH, Wálter Fanganiello. Além do Charlie Hebdo. In: Revista Carta Capital, n. 833. Ano XXI. 21 de janeiro de 2015, p. 19.

${ }^{43}$ Segundo Maierovitch (ibid.), a distinção entre islâmicos pacíficos e terroristas parece passar despercebida pela direita, mesmo no que tange aos fatos relacionados ao atentado. "O policial de origem árabe e religião islâmica Ahmed Merabet enfrentou até a morte, na calçada defronte à sede do semanário, os dois irmãos Kouachi. Seus familiares, em entrevista coletiva que Le Pen prefere ignorar, ressaltaram: 'Ahmed era de fé islâmica e os seus assassinos uns falsos islamitas, pois o Islã é uma religião de paz'". Deve-se notar que os atos terroristas são condenados pelo Islã oficial e muitos muçulmanos têm um comportamento pacífico.

${ }^{44}$ Tratado de Schegen prevê a circulação livre de cidadãos pela União Europeia.

${ }^{45}$ BESSEL, Lucas. PURCHIO, Luisa. Em defesa da liberdade. In: Revista Isto é, n. 2.354. $14 / 1 / 2015$, p. 60.

${ }^{46}$ AQUINO, Ruth de. A liberdade abatida a tiros. In: Revista Época, n. 866.12 de janeiro de 2015, p. 63.
} 


\section{Método do Charlie Hebdo de combate ao extremismo}

Ao analisar charges que relatam fatos cotidianos, Safatle ${ }^{47}$ não compreendeu o método muitas vezes utilizado pelos chargistas, de citar a notícia, reinterpretá-la e recombiná-la tendo em vista o humor e a crítica.

Para Tonneau ${ }^{48}$, apenas fora do contexto os cartuns do Charlie Hebdo podem parecer racistas ou islamofóbicos. "Charlie Hebdo defendeu continuamente a causa das minorias e lutou incansavelmente para que todos os imigrantes ilegais ganhassem o direito definitivo de permanência", ou seja, Charlie tenta trazer por meio do humor uma solução para o problema. Assim, não deveriam ser condenados por terem causado sua própria morte. Segundo ele, o ataque ganha um caráter muito mais trágico se considerarmos que não foi direcionado para jornais de extrema direita franceses atuais, como Minute, Valeurs ou Actuelles, que sempre misturam árabes, muçulmanos e fundamentalistas ${ }^{49}$, mas direcionado a um jornal que luta contra o racismo. Além disso, o ataque pode ser explorado pela extrema direita e pelo governo, como "oportunidade para criar uma falsa unanimidade em uma sociedade profundamente dividida". Inspirado em Bush, o primeiro ministro da França Manuel Vals anuncia que "está em guerra contra o terror" e François Hollande ${ }^{50}$ declara que "os autores dessas ações serão perseguidos enquanto for necessário... É preciso formar um bloco unido".

O alvo dos cartunistas era principalmente o extremismo islâmico. Moneyron $^{51}$ analisa as capas do Charlie Hebdo em 2014 e constata que nenhuma delas trata da questão do Islã ou da comunidade islâmica na França. As capas, em geral, traziam situações da política francesa. Oito dessas capas, contudo, tratavam de extremistas.

Devemos considerar as charges publicadas no Charlie Hebdo, principalmente direcionadas contra o extremismo islâmico. A ilustração da capa de $1^{\circ}$ de outubro de 2014 pode ser considerada ofensiva por trazer Maomé, mas não é exatamente islamofóbica, pois trata dos extremistas e sua interpretação pessoal do Alcorão, que nem mais permite que eles reconheçam o

\footnotetext{
${ }^{47}$ Ibid.

${ }^{48}$ TONNEAU, Olivier. On Charlie Hebdo: a letter to my British friends. The Guardian. Edição de 13 de janeiro de 2015.2 Disponível em: http://www.theguardian.com/commentisfree/2015/jan/13/charlie-hebdo-solution-muslimsfrench-arab-descent-newspaper-fight-racism. Acessado em 15/3/2015.

49 Segundo Tonneau (ibid.), apenas quando pararem de confundir árabes, muçulmanos e fundamentalistas será possível evitar que a crítica aos fundamentalistas sobrecaia sobre os árabes. "Esta é a razão pela qual as distinções devem ser claras". Fundamentalismo islâmico vem crescendo muito. Tonneau (Ibid.) mostra que seu alvo principal são os próprios islâmicos, que não querem ser confundidos com seus assassinos. Tivemos inclusive na web manifestações de diversos muçulmanos que se posicionaram contra o terrorismo e se diferenciaram com o slogan "Não em meu nome" ( "not in my name"). Assim como a religião cristã, o extremismo islâmico trouxe muitos prejuízos ao mundo islâmico em termos de direitos individuais. Também não devem ser confundidas raça e religião.

${ }^{50}$ Apud CARTA, Gianni. Os fanáticos do apocalipse. In: Revista Carta Capital, n. 832. Ano XX. 14 de janeiro de 2015, p. 45.

51 MONEYRON, Josselin. A year in the merde. In: The Hooded Utilitarian: a pundit in every panopticon. Disponível em: http://www.hoodedutilitarian.com/2015/01/a-year-in-the-merde/. Acessado em 2/2/2015.
} 
próprio Maomé após seu retorno. Além disso, temos um resultado irônico na incapacidade do muçulmano radical em reconhecer o profeta. Já que o profeta não é nunca representado, não há como reconhecê-lo.

Charb $^{52}$ (apud MONEYRON, 2015) mostra sua indignação contra o tratamento (preconceituoso) dado aos islâmicos não radicais.

Não aguento quando pedem aos "islâmicos moderados" que expressem sua condenação ao terrorismo. Não existe um islâmico moderado. Apenas islâmicos com sua herança islâmica, que jejuam durante o Ramadan como eu celebro o Natal. Eles agem como cidadãos. Eles protestam conosco, votam contra idiotas de direita... Seria como se me pedissem para votar como um católico moderado, só porque eu fui batizado. Eu não sou católico moderado. Eu não sou nada católico.

Podemos pensar também nos cartunistas do Charlie Hebdo como aqueles que se levantaram contra as tendências teocráticas dominantes. A igreja católica, por exemplo, realizou forte oposição contra o casamento homossexual e recebeu resposta imediata no Charlie Hebdo na edição de 9 de janeiro de 2013.

As acusações de racismo, por sua vez, parecem ser infundadas. Antes de sua morte, Charb ${ }^{53}$ deixou escrito um livro em que condena o racismo. Mostra que, na França, o ímpeto racista foi amplamente divulgado por Sarkozy no âmbito de seu discurso sobre a identidade nacional. Para Charb, o discurso sobre a islamofobia teria como objetivo fazer com que as vítimas se afirmassem muçulmanas, mas "se amanhã os muçulmanos da França se converterem ao catolicismo ou renunciarem a qualquer religião, isso não vai mudar o discurso racista: os estrangeiros ou os franceses de origem estrangeira serão sempre designados como responsáveis por todos os males". O problema nao estaria na Bíblia ou no Alcorão, mas nas interpretações que são realizadas deles pelos extremistas.

A charge sobre Christiane Taubira (Ministra da justiça do governo de Hollande) fazia uma alusão à comparação racista realizada por um membro do Front National (partido de extrema direita de Le Pen), onde são contrapostos um chipanzé e a foto da ministra, ato que foi condenado e o autor processado. O combate da islamificação da França em nome da secularização francesa passou a ser o mote da filha de Le Pen, Marine. Charb, ao cotejar o ocorrido com Taubira, enfatiza todo o movimento violento e racista relacionado ao partido, com distorções da referência a Marine Le Pen - ao invés de "Coalizão Azul Marinho" ("Rassemblement Bleu Marine"), "Coalizão Azul Racista" ("Rassemblement Bleu Raciste") - e o símbolo do Front National - fogo estilizado com as cores da bandeira francesa.

\footnotetext{
${ }^{52}$ Apud MONEYRON. Op. cit.

53 Apud LANCELIN, Aude. Exclusif. Le testament de Charb. In: Bibliobs. 15/4/2015. Disponível em: http://bibliobs.nouvelobs.com/actualites/20150414.OBS7182/exclusif-le-testament-decharb.html. Acessado em 15/5/2015.
} 
O problema é que existe o risco de ser mal compreendido ao trazer imagens chocantes para frisar uma postura antirracista, conforme mostra Jeet Heer ${ }^{54}$, o que também ocorre em Robert Crumb.

Referências negativas ao racismo e colonialismo europeu não são recentes no âmbito do Charlie Hebdo e Hara-Kiri. Nesse sentido, poderíamos indicar, por exemplo, a charge veiculada na capa da edição de 22 de outubro de 2014. Para se referir, na mesma ilustração, aos crimes de Boko Haram na Nigéria e a posição da extrema direita francesa em condenar a política do wellfare, Riss se utiliza de uma imagem racista.

Podemos perceber essa prática de forma leve na ilustração para capa de Cabu para a edição de 29 de outubro de 2014, em que Nicolas Sarkozy e Marine Le Pen fazem buracos em um barco cheio de refugiados. A imagem mostra óbvia simpatia pelos refugiados e indica também a posição crítica desses cartunistas em relação às soluções dos programas políticos racistas de Sarkozy (e não qualquer tipo de associação a ele como se sugere no livro de Tissot \& Tévanian) e de Le Pen. Em outra capa de 26 de setembro de 2014, temos a comparação do estado islâmico com o "estado sarkozyco".

As caricaturas consideradas desrespeitosas por alguns tinham como objetivo a denúncia do extremismo religioso. Na prática de Boko Haram, em organização fundamentalista islâmica terrorista, temos o desrespeito ao ser humano, à mulher e às meninas. A partir de distorções do Alcorão, temos ali uma permissividade ao abuso sexual sem limites, cenário que já se deu no embate entre muçulmanos e cristãos em outros momentos no século XX como no extermínio armênio, por volta de 1915. Essa distorção é condenada veementemente pelos cartunistas do Charlie Hebdo por meio das charges, incluindo aquela específica que trata das escravas sexuais de Boko Haram e de Maomé de quatro - um de seus trabalhos mais radicais -, que apesar de criticar a distorção da religião, também ofende muçulmanos de forma geral.

\section{Conclusão}

O acúmulo de décadas de trabalho de alguns dos desenhistas do Charlie Hebdo atinge um ponto final com suas mortes. Existe, contudo, um novo panorama posterior a esse evento em que os conflitos em torno das questões religiosas tendem a se exacerbar. Porém, o semanário continua a publicar charges e quadrinhos críticos. Agora, com maior reflexividade.

Temos no Charlie Hebdo uma dialética que parte de uma ideia de humor bête et méchant, porém, com o passar do tempo, se adéqua em parte a uma moral socialmente instituída. Em ambas as fases, essa ideia, ao ser externalizada, ganha objetivação nas charges. Com a morte dos desenhistas, temos não o fim do semanário, mas a possibilidade de rever toda a sua história com uma tomada de consciência de seus valores e seus erros. A síntese de sua ideia de humor e a natureza objetiva no cartum permitem a reflexividade, percebida no mundo todo: "Je suis Charlie", que se revela por meio do próprio

${ }^{54}$ Apud MONEYRON. Op. cit. 
desenho. Resultado semelhante também ocorreu na época do atentado anterior, na capa de dezembro de 2011 do número 1.012 do Charlie Hebdo no qual um muçulmano beija na boca um desenhista do Charlie com a inscrição: "O amor mais forte que o ódio" ("Lamour plus fort que la haine"). A autorreflexão também esteve presente no editorial de Biard ${ }^{55}$ da edição posterior ao atentado:

Na última semana, Charlie, jornal ateu, alcançou mais milagres do que todos os santos e profetas reunidos... Vocês têm em mãos o jornal que sempre fizemos... Os sinos de Notre Dame tocaram em nossa homenagem. Nesta semana, Charlie se levanta através do mundo, mais alto do que as montanhas... Nós temos frequentemente tentado rir, pois é isso que fazemos melhor...

Porém, expõe que o sangue dos desenhistas mortos ainda está quente. Com o ataque, Charlie Hebdo passou a simbolizar, segundo Bernard-Henri Levy ${ }^{56}$ algo muito mais amplo do que a sátira dos cartuns: uma resolução em manter a liberdade de expressão mesmo em face de ameaças mortais.

Talvez nessa proximidade do fim esteja o momento mais propício para compreender o seu começo ou o novo recomeço, como ser bête et méchant e como serão as novas encarnações do Charlie. Na morte e na retomada de sua essência original, temos a emergência de novas roupagens e novas problematizações. Mostra que a manutenção dessa essência ou sua idealização talvez não seja mais possível. Talvez o cuidado e o medo agora sejam maiores ou a coragem que tanto os marcou continue a ser preponderante.

Intensifica-se também com as mortes a impressão de que os dois polos abordados pela comissão de laicidade deveriam ser respeitados, a esfera pública e o direito à prática religiosa. Posicionamentos polêmicos, como a proibição do uso do véu, por exemplo, são justamente os aspectos incorporados à sátira do Charlie Hebdo. A reação contra esse tipo de coibição se dá de forma imediata por meio de ameaças, sequestros e execuções por parte de extremistas religiosos.

O posicionamento atual do Charlie Hebdo, contudo, não é tão "estúpido e desagradável" quanto no passado e, sim, uma prática que também se baseia em valores morais instituídos e assumidos pelos próprios cartunistas da publicação. Assim, ele pode ser pensado como aquele que auxilia na garantia de uma imposição de limites para a religião e para o extremismo religioso. Contudo, também pode se enquadrado como estopim de conflitos que se dão pela prática do humor, localizado no âmbito público. Essas interpretações podem ser questionadas: se existe a possibilidade de o humor do Charlie causar tamanha influência ou se esse humor tem realmente tamanho alcance.

\footnotetext{
${ }^{55}$ BIARD, Gerard. O aperitivo. In: Charlie Hebdo, n. 1.178. 14 de janeiro de 2015, p. 5.

56 LEVY, Bernard-Henri. Charlie Hebdo is Western society at its best and worst. In: What everyone gets wrong about Charlie Hebdo and racism. Vox World. Disponível em: http://www.vox.com/2015/1/12/7518349/charlie-hebdo-racist. Acessado em 22/3/2015.
} 
A charge do Charlie Hebdo também não pode ser considerada arte degenerada como queria Hegel, arte que chega a um fim por ser comédia. Certamente, ela não será idolatrada e adorada como se fosse divina. Não mais a bela arte, mas a bela arte do humor. Trata-se de uma manifestação infinitamente bête et méchant apresentada como charge bem finita - mas com algumas sobreposições de camadas significativas que se multiplicam ao serem interpretadas pelo leitor - e, por outro lado, uma filosofia bête et méchant que tenta se impor sobre a religião com a crítica e a autorreflexão.

Charlie Hebdo traz o divino e incorpora preceitos religiosos para criticálos e questionar sua autoridade. Trata de um ideal de laicidade a ser respeitado como verdade. A insistência da dessacralização e o tom de blasfêmia na prática humorística do Charlie Hebdo parecem apontar para o movimento de afastamento que se deu da arte em relação ao culto sagrado. Redunda no fim de uma arte que se articula em torno da religião. Contudo, aqui temos um novo tipo de verdade pautada pelo compromisso com a igualdade, pela crítica política aguda e pelo confronto com o fundamentalismo, a que eles, com coragem e ousadia, não se curvam. O humor ácido e corrosivo talvez seja a única forma de verdade sobre os aspectos mais polêmicos da política e religiosidade contemporâneas.

Temos, então, uma arte humorística que traz uma verdade própria, apresentada em uma configuração sensível graças a um processo criativo e intuitivo dos cartunistas. Por outro lado, temos um conflito para os religiosos, em que a intuição interiorizada e apreendida da sátira é recordada - nem sempre compreendida -, recombinada em associações livres graças à imaginação e memorizada. Por parte dos cartunistas, seus procedimentos, como uma religiosidade particular, permitirão que toda intuição humorística proveniente do sensível seja recombinada com universalizações de outras recordações. A filosofia humorística do Charlie envolve esses dois momentos, de uma configuração sensível finita que emerge a partir de um processo intuitivo e ao mesmo tempo de associações livres infinitas dessa configuração com outras, o que, como vimos, resulta em charges que serviram como armas em uma guerra que redundou em mortes e nas possibilidades de autocrítica, "Je suis Charlie".

Contudo, ao tentar colocar limites para a prática religiosa por meio do humor, Charlie Hebdo parece assumir um papel radical. Seria possível conseguir destruir o extremismo por meio do desenho? Também podemos tentar compreender as charges do Charlie Hebdo como aquelas que emergem a partir do impulso. Considerando as relações humanas, seus trabalhos se aproximam do drama. No caso, o drama de uma sociedade que colhe os frutos de seus próprios atos.

Não se pode falar em um fim sem que se considere um começo: aqui temos sobrevivência e morte. Com artistas que expõem sua opinião e, mesmo sabendo que correm risco, pagam com a própria vida, temos uma proximidade com a concepção do humor como a destruição da arte por ela mesma.

Essa destruição da arte por ela mesma, como mostrou Hegel para a comédia, talvez só faça sentido no humor bête et méchant, quando Cavanna ${ }^{57}$

${ }^{57}$ Apud WESTON, Jane. Op. cit., p.110. 
desconsidera toda a sacralidade de tudo para que um riso feroz e amargo possa emergir e "exorcizar os velhos monstros".

\section{Sobre 0 autor}

Fabio Mourilhe Correio é pesquisador de pós-doutorado da EBA/UFRJ, onde desenvolve trabalhos sobre Angelo Agostini, a Academia Imperial de Belas Artes e a convergência de humor e crítica de arte no século XIX. Doutor em Filosofia pelo IFCS/UFRJ, sua tese $A$ estética do grotesco nos quadrinhos, defendida em 2014, trata de uma ampliação de seu estudo sobre o tema realizado em 2011. E-mail: funkstroke@yahoo.com.

Artigo recebido em 24 de novembro de 2015.

Aprovado em 15 de junho de 2016. 